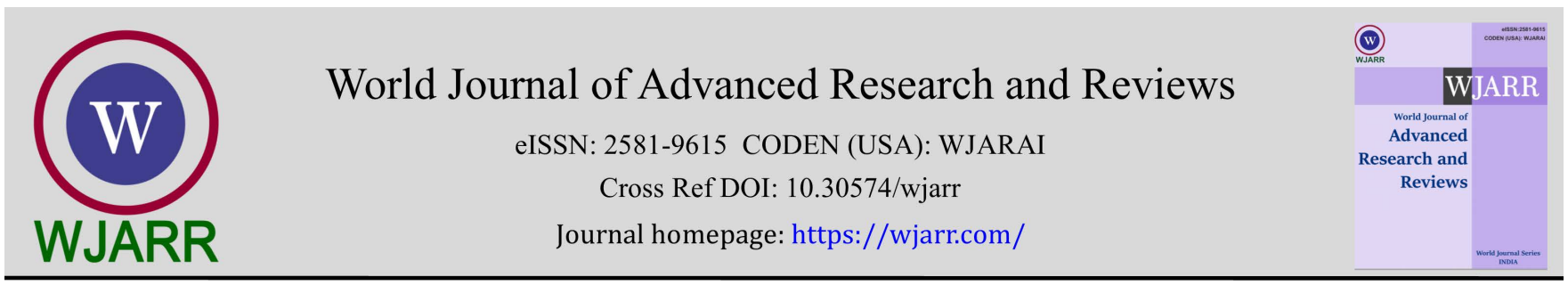

(RESEARCH ARTiClE)

Check for updates

\title{
Oral findings in patients with chronic kidney disease: A cross-sectional descriptive study in Cuenca, Ecuador
}

\author{
Yadira Lucía Piedra Bravo 1, *, Diana Estefania Sinchiguano Velecela 2, Ana Cristina Criollo Velecela 2, María \\ Gracia Ordoñez Pesántez ${ }^{3}$ and María Paula Piedra Idrovo ${ }^{3}$ \\ ${ }^{1}$ Health Research, Department of Diagnosis and Stomatology, Faculty of Dentistry, University of Cuenca, Cuenca, Ecuador. \\ 2 Faculty of Dentistry, University of Cuenca, Cuenca, Ecuador. \\ ${ }^{3}$ General Dentistry Faculty of Dentistry, University of Cuenca, Cuenca, Ecuador.
}

World Journal of Advanced Research and Reviews, 2021, 11(02), 373-379

Publication history: Received on 21 July 2021; revised on 26 August 2021; accepted on 28 August 2021

Article DOI: https://doi.org/10.30574/wjarr.2021.11.2.0400

\begin{abstract}
Objective: To determine the different oral findings in patients with renal insufficiency, chronic.

Methods: A descriptive cross-sectional study was carried out that included 123 individuals who were diagnosed with renal insufficiency, chronic and underwent dialysis treatment at the Renal Services Unit of the Austro of the city of Cuenca-Ecuador. Once the study was approved by the Research Directorate of the Faculty of Dentistry (DIFO) of the University of Cuenca (code UC-DIFO-PROY-17-010), the oral cavity of the patients was examined to detect gingival enlargement non-inflammatory, hemorrhagic lesions (purpura and ecchymosis), uremic stomatitis and oral candidiasis. Data analysis was performed using the IBM-SPSS Statistics 20.0 program for Windows software (IBM Corporation, Armonk, NY, USA); the results were presented in simple distribution tables by calculating their percentage frequency.
\end{abstract}

Results: Of the 123 subjects who participated in this study, 52\% (n=64) were women, while 48\% (n=59) were men. The mean age of the study population was 60.2 (SD: 14.6) years. Oral findings were described in 74\% (n=91) of patient's with renal insufficiency, chronic. Among them were: non-inflammatory gingival enlargement (64.7\%) ( $n=57)$, hemorrhagic lesions such as purpura and ecchymosis (57.7\%) $(n=71)$, uremic stomatitis $(10.6 \%)(n=13)$ and oral candidiasis $(8.1 \%)(n=10)$.

Conclusion: Patients with renal insufficiency, chronic present important oral findings that should be identified and treated during dental practice.

Keywords: Oral findings; Renal insufficiency; Chronic; Dialysis; Prevalence

\section{Introduction}

Chronic Kidney Disease (CKD) is a generic term used to describe the clinical syndrome secondary to alterations in the structure and/or function of the kidney [1]. It is considered as a renal dysfunction characterized by a reduced glomerular filtration rate, increased urinary albumin excretion, or both [2].

In recent years, a significant increase in the frequency of CKD has been noted; its prevalence worldwide is estimated to be between $8 \%$ and $16 \%$ of the adult population [2-4]. In fact, local prevalence studies have reported that CKD reached

\footnotetext{
${ }^{*}$ Corresponding author: Yadira Lucía Piedra-Bravo

Health Research, Department of Diagnosis and Stomatology, Faculty of Dentistry, University of Cuenca, Cuenca, Ecuador. 
$10.6 \%$ [5]. This situation, together with the high health care costs derived from its treatment, means that this disease, considered catastrophic, has become a worldwide public health problem [6].

It is an irreversible and progressive condition that in most cases remains asymptomatic and silent, manifesting itself only in its advanced stages [1,7]. Therefore, it is recommended that, in at-risk populations such as hypertensive patients, diabetics, patients with hypertensive, diabetic patients, with evidence of urinary obstruction or with an important family history, it is recommended that an early diagnosis of the disease be made to avoid its progression and complications $[5,8,9]$. In practice, when CKD progresses to end-stage disease, the therapeutic options for patients include renal replacement therapy (dialysis or transplantation) or palliative care $[3,8]$.

This terminal stage is expressed through the so-called "uremic syndrome" characterized by a generalized physiological imbalance that manifests itself, among other things, with neurological, cardiovascular and skin alterations, proteincalorie malnutrition, anemia and osteodystrophy [10].

Thus, if CKD leads to a general deterioration of health, the oral cavity is no exception. In fact, researchers estimate that about $90 \%$ of renal patients show oral symptoms [11-13].

These oral findings are varied and are related to the conditions of the disease itself, to the effects of therapy, or to both [14]. Among these findings, some have been described as: geographic tongue, dry mouth sensation, taste changes, mucosal pallor, uremic breath, dental calculus, gingival bleeding, dental caries and infections such as candidiasis and recurrent herpes [7, 14-18].

Therefore, although a considerable amount of scientific evidence affirms that CKD is a systemic disease frequently associated with a set of oral findings $[16,18]$, the subject has not yet been fully addressed and more reports describing the frequency of these findings in different populations are needed.

Thus, this study was designed with the objective of determining the different oral findings in patients with chronic renal failure undergoing dialysis treatment at the Austro Renal Services Unit in Cuenca, Ecuador.

\section{Methods}

A descriptive cross-sectional design study was carried out. The universe consisted of 180 patients registered in the database of the Renal Services Unit of Austro of Cuenca-Ecuador.

The finite population formula was used for the sample calculation with a $5 \%$ probability of error and a confidence level of $95 \%$. The sample size was defined with a total of 123 individuals; the convenience sampling technique was applied with the following criteria: stable patients, over age, diagnosed with chronic renal failure undergoing dialysis therapy. Cases of patients treated with chemo and/or radiotherapy were excluded.

To collect the data was designed as an instrument a form with the study variables: age, sex, non-inflammatory gingival enlargement, oral candidiasis, uremic stomatitis and hemorrhagic lesions.

The examination of the buccal mucosa was performed using the direct observation technique by the two examiners (MPPI /MGOP). A flat intraoral mirror No.5 $(24 \mathrm{~mm})$ with a simple handle (Hu-Friedy), a frontal light placed on the head and personal protective equipment were used.

The variable non-inflammatory gingival enlargement was evaluated by means of the application of a North Carolina periodontal probe (Hu-Friedy MFG. CO.LLC, Chicago, Illinois, USA). Probing was performed on the 6 surfaces of each tooth present in the mouth; the presence of this lesion was considered to be present when a probing depth greater than $3 \mathrm{~mm}$ was obtained, without bleeding or loss of attachment.

To define the presence of oral candidiasis, examiners inspected the oral mucosa for atrophic and hyperplastic clinical forms. When the clinical lesion was suggestive of Candida-associated fungal infection, the definitive diagnosis was established through the exfoliative cytology technique. For this, the examiners used a cotton swab (cytoswab) enclosed in Stuart's transport medium (Labware Manufacturing Co. Ltd R\&D). The sample obtained was sealed and coded, preserved on ice at a temperature of approximately $4^{\circ} \mathrm{C}$ and sent to the laboratory for mycological culture processing (GM Clinical Laboratory ISO 9001:2015). Oral candidiasis was considered when the culture result was positive 
(presence of whitish, cottony yeast-like colonies). Meanwhile, when the swabbing of the clinical lesion was negative to mycological culture, it was established as uremic stomatitis.

Finally, the presence of hemorrhagic lesions in the buccal mucosa was considered. For their diagnosis, each one was observed and measured using a North Carolina periodontal probe (Hu-Friedy MFG. CO.LLC, Chicago, Illinois, USA). Punctiform lesions were defined as purpura and diffuse lesions with an extension greater than 2-3 cm were defined as ecchymosis.

To ensure the reliability of the clinical measurements, and in order to evaluate the degree of concordance of the observations, the respective inter-observer calibration was performed. For this purpose, a group of 20 patients with the expected conditions was preselected. The calibration exercises were performed by the two examiners (MPPI /MGOP) and were executed for two occasions on successive days. For categorical (qualitative) variables, the kappa coefficient was calculated ( $\mathrm{k}=0.56 /$ moderate) and for continuous data the intraclass correlation coefficient was calculated (ICC= 0.62 (good).

The information obtained was analyzed statistically using the IBM-SPSS Statistics 20.0 program for Windows software (IBM Corporation, Armonk, NY, USA). The data were subjected to analysis by calculating their percentage frequency.

\section{Results}

123 patients with chronic renal failure participated in this study; 64 (52\%) were female and 59 (48\%) were male. Their average age was 62 years (range, 19-92 years). Of the total sample, 75 individuals (61\%) were younger than 65 years of age (Table 1).

Table 1 Characterization of the study population according to sex and age. Renal Services Unit of Austro. Cuenca, Ecuador (2018)

\begin{tabular}{|c|c|c|}
\hline & $n=123$ & $\%$ \\
\hline \multicolumn{3}{|l|}{ Sex } \\
\hline Female & 64 & 52 \\
\hline Male & 59 & 48 \\
\hline \multicolumn{3}{|l|}{ *Age } \\
\hline Adults $18-64$ years & 75 & 61 \\
\hline Adults $\geq 65$ years & 48 & 39 \\
\hline Total & 123 & 100 \\
\hline
\end{tabular}

The clinical examination of the subjects participating in this study determined the frequency and percentage of oral findings in patients with chronic renal failure. Thus, non-inflammatory gingival enlargement reached 64\%, hemorrhagic lesions of the oral mucosa (purpura and ecchymosis) $57.7 \%$, uremic stomatitis $10.6 \%$, and oral candidiasis $8.1 \%$.

Excluding non-inflammatory gingival enlargement, which is logically located at the level of the gingiva, the anatomical areas of the oral mucosa that most frequently present manifestations of chronic renal insufficiency were jugal mucosa, vestibular sulcus, and hard palate (Table 3).

Finally, our findings revealed that of the 123 patients with chronic kidney disease, 91 (74\%) presented at least one finding in their oral mucosa (Table 4) 
Table 2 Frequency and percentage of oral findings in patients with chronic renal failure. Renal Services Unit of Austro. Cuenca, Ecuador (2018)

\begin{tabular}{|c|c|c|}
\hline & $n=123$ & $100 \%$ \\
\hline \multicolumn{3}{|c|}{ *Non-inflammatory gingival enlargement } \\
\hline Present & 57 & 64.7 \\
\hline Absent & 31 & 35.3 \\
\hline \multicolumn{3}{|c|}{ Hemorrhagic (purpura y ecchymosis) } \\
\hline Present & 71 & 57.7 \\
\hline Absent & 52 & 42.3 \\
\hline \multicolumn{3}{|c|}{ Uremic stomatitis } \\
\hline Present & 13 & 10.6 \\
\hline Absent & 110 & 89.4 \\
\hline \multicolumn{3}{|c|}{ Oral candidiasis } \\
\hline Present & 10 & 8.1 \\
\hline Absent & 113 & 91.9 \\
\hline
\end{tabular}

Table 3 Oral findings in patients with chronic renal failure according to the anatomical area affected. Renal Services Unit of Austro. Cuenca, Ecuador (2018)

\begin{tabular}{|c|c|c|}
\hline & $\mathbf{N}$ & $\%$ \\
\hline \multicolumn{3}{|c|}{ Hemorrhagic lesions (purpura y ecchymosis) } \\
\hline Jugal mucosa & 44 & 61.9 \\
\hline \multicolumn{3}{|l|}{ Uremic stomatitis } \\
\hline Vestibular sulcus & 9 & 69.2 \\
\hline \multicolumn{3}{|l|}{ Oral Candidiasis } \\
\hline Hard palate & 7 & 70.0 \\
\hline
\end{tabular}

Table 4 Frequency and percentage of oral findings in patients with chronic renal failure. Renal Services Unit of Austro. Cuenca, Ecuador (2018)

\begin{tabular}{|c|c|c|}
\hline & $\mathrm{n}=123$ & $100 \%$ \\
\hline \multicolumn{3}{|c|}{ Oral findings in patients with chronic renal failure } \\
\hline Presents & 91 & 74 \\
\hline Absents & 32 & 26 \\
\hline
\end{tabular}

\section{Discussion}

Being considered as a systemic disease, CKD occurs along with a wide spectrum of concomitant oral findings associated with the accumulation of uremic toxins and the presence of other determinants such as dehydration, aging, drugs, immunosuppression, poor oral hygiene [14, 16, 19]. 
Previous studies conducted in India by Patil et al., in Pakistan by Gichki et al., and in Colombia by Rebolledo et al., suggest that virtually all patients with CKD had clinical oral findings of the disease $[14,17,20]$. These results differ from those obtained in this study. In fact, our results revealed that $74 \%$ of patients with CKD presented oral manifestations, this interesting discrepancy should be interpreted with caution. The difference could be related to the event that the work in mention considered for their analysis certain variables that could have been linked to subjective concepts such as dry mouth sensation, changes in taste perception, mucosal pallor, and halitosis or because they evaluated conditions that are not necessarily associated with CKD, and that of themselves are frequent in the general population such as bacterial plaque, calculus, gingival bleeding, and dental caries, while our research was based fundamentally on clinical manifestations that appear in the oral mucosa. Meanwhile, similar results to ours were reported by research in an iranian population showing that $78 \%$ of their study population presented oral findings [16].

This investigation found that non-inflammatory gingival enlargement appeared as the most frequent oral mucosal lesion in dentate patients with CKD (64.7\%). Although the literature reviews shows that these results are consistent with those reported by other authors [7,21-23], it should be noted that this enigmatic condition is usually the result of the combination of several risk factors, including drugs frequently used in patients with chronic renal failure, such as calcium channel blockers and cyclosporins [24].

Regarding the study of hemorrhagic lesion of the buccal mucosa, our results revealed that their prevalence reached $57.7 \%$. The present work individually analyzed hemorrhagic lesions of soft tissues according to their size in purpura and ecchymosis [21]. Our data reported that purpura reached $50.4 \%$ and ecchymosis $7.3 \%$. The study by Lecca et al., combined petechiae and ecchymosis in a single variable and revealed a prevalence of 36.9\% [22]. In contrast, Belazelkovska reported an extremely high prevalence of these lesions at $90 \%$. These discrepancies could be due to the lack of a specific methodology used for identification of these entities that often coexist [23]. Hemorrhagic lesions are frequent in patients with CKD due to conditions such as abnormal platelet adhesion and aggregation, thromboxane and prostacyclin abnormality [25].

Regarding oral candidiasis, our findings showed that it reached a prevalence of 8.1\%; this data is relevant since, if we compare it with other research similar to ours, the authors report a much higher prevalence this between $15 \%$ and $28 \%$ $[14,26]$. If we compare the results, it is noticeable that there important differences. This disparity could be due to the methods used for diagnosis. In our case, the prevalence is lower since it was considered oral candidiasis only when the microbiological culture result was positive. Similar results to ours have been reported by Belazelkovska et al., the authors report a prevalence that reaches $10 \%$ [23], it should be noted that both investigations used microbiological culture as a diagnostic method.

Our data reported a prevalence of uremic stomatitis that reached $10.6 \%$ in contrast to the results published in similar studies by Gichki et al., Rebolledo et al., Lecca et al., and Oyetola et al., where the prevalence was 74\%, 12.5\%, 32.8\%, and $2 \%$ respectively $[14,20,22,26]$. This finding shows a discrepancy between the results, which could be explained by the fact that there is no clear definition or this entity since multiple authors consider it in different ways and with different clinical variant. On the other hand, as its probable cause is the high concentrations of ammonium and urea in the saliva of decompensated patients, this study did not find a notable prevalence since it included stable patients, undergoing hemodialysis treatment. This work considered oral ulcers that were negative to microbiological culture as a clinical variant of uremic stomatitis.

The limitations of this study are that the participants belonged to a single referral unit the public health network of the city of Cuenca, Ecuador, making it difficult to infer our results. On the other hand, although our data show that $74 \%$ of patients with chronic renal failure presented at least one finding in their oral mucosa, the descriptive design of this study does not allow us to associate these findings to this condition. It is known that the oral findings reported in this study could be associated with other conditions such as nutritional status, drugs, infections, vitamin deficiencies, use of dental protheses, among others. Precisely this work constitutes a platform for the generation of news studies that deepen the knowledge of chronic renal failure and its systemic manifestation that include oral findings.

\section{Conclusion}

In conclusion, patients with chronic renal failure present important oral findings that should be identified and treated during dental practice to avoid further complications in their health status. 


\section{Compliance with ethical standards}

\section{Acknowledgments}

The authors would like to thank the directors and patients of the Renal Services Unit of Austro of Cuenca- Ecuador for providing us with the facilities to carry out this study.

\section{Disclosure of conflict of interest}

The authors have declared that there is no conflict of interest.

\section{Statement of ethical approval}

The present study was designed under the bioethical foundations of research on human beings of nonmaleficence, beneficence, autonomy and justice proclaimed in the Belmont Report and the Declaration of Helsinki. Through an informed consent form, each participant was informed of a detailed description of the study, the possible risks to which he/she would be exposed, as well as the benefits of his/her participation; the confidentiality of the data obtained and the anonymity of the participants were preserved.

\section{Statement of informed consent}

Participants expressed their willingness to participate on the informed consent form designed for this purpose. The present study was approved by the Research Directorate of the Faculty of Dentistry (DIFO) of the University of Cuenca on November 24, 2017 (code UC-DIFO-PROY-17-010).

\section{References}

[1] Ammirati AL. Chronic Kidney Disease. Rev Assoc Med Bras. 2020; 66(1): 3-9.

[2] Jha V, Garcia-Garcia G, Iseki K, Li Z, Naicker S, Plattner B, et al. Chronic kidney disease: global dimension and perspectives. The Lancet. 2013; 382(9888): 260-272.

[3] Webster AC, Nagler EV, Morton RL, Masson P. Chronic kidney disease. The Lancet. 2017; 389(10075): 1238-1252.

[4] Coresh J, Selvin E, Stevens LA, Manzi J, Kusek JW, Eggers P, et al. Prevalence of chronic kidney disease in the United States. Jama. 2007; 298(17): 2038-2047.

[5] Guzmán-Guillén K, de Córdova-Aguirre JF, Mora-Bravo F, Vintimilla-Maldonado J. Prevalencia y factores asociados a enfermedad renal crónica. Rev Med Hosp Gen Méx. 2014; 77(3): 108-113.

[6] Pérez-Oliva Díaz JF, Portal Miranda JA. Enfermedad renal crónica: estrategia nacional para enfrentar este importante problema de salud. Rev Haban Cienc Méd. 2010; 9(2): 140-142.

[7] Proctor R, Kumar N, Stein A, Moles D, Porter S. Oral and dental aspects of chronic renal failure. J Dent Res. 2005; 84(3): 199-208.

[8] Levey AS, Becker C, Inker LA. Glomerular filtration rate and albuminuria for detection and staging of acute and chronic kidney disease in adults: a systematic review. Jama. 2015; 313(8): 837-846.

[9] Noble R, Taal MW. Epidemiology and causes of chronic kidney disease. Medicine. 2019; 47(9): 562-566.

[10] Henao CM, Restrepo CA. Enfermedad renal crónica. Nefrología básica. 2nd ed. Bogota: La Patria S.A. 2018.

[11] Castillo LG, Martinez CA, Ochoa C, Perez J, Bayardo R. Manifestaciones orales en niños con enfermedad renal crónica.Rev Tamé. 2016; 4(12): 417-421.

[12] Hajheydari Z, Makhlogh A. Cutaneous and Mucosal Manifestations in Patients on Maintenance Hemodialysis A Study of 101 Patients in Sari, Iran. Iran J Kidney Dis. 2008; 2(2): 86-90.

[13] La Rosa García Ed, Mondragón Padilla A, Irigoyen Camacho ME, Bustamante Ramírez MA. Lesiones bucales en un grupo de pacientes con trasplante renal. Med Oral Patol Oral Cir Bucal. 2005; 10(3): 196-204.

[14] Gichki AS, Ahmed K, Ali NA. Oral Findings in Chronic Kidney Disease In Nephrology Department Sandeman Provincial Hospital, Quetta. J Saidu Med Coll. 2020; 9(2). 
[15] Davidovich E, Schwarz Z, Davidovitch M, Eidelman E, Bimstein E. Oral findings and periodontal status in children, adolescents and young adults suffering from renal failure. J Clin Periodontol. 2005; 32(10): 1076-82.

[16] Afroozi B, Ghapanchi J, Khorshidi H, Esnaashari N, Faghih M. Oral findings in hemodialysis patients; a crosssectional study in Shiraz, Iran. J Nephropathol. 2018; 7(4): 263-267.

[17] Patil S, Khaandelwal S, Doni B, Rahuman F, Kaswan S. Oral manifestations in chronic renal failure patients attending two hospitals in North Karnataka, India. Oral Health Dent Manag. 2012; 11(3): 100-106.

[18] Asha V, Latha S, Pai A, Srinivas K, Ganapathy K. Oral manifestations in diabetic and nondiabetic chronic renal failure patients on hemodialysis. JIAOMR. 2012; 24(4): 274-279.

[19] Kuravatti S, David MP, Indira A. Oral manifestations of chronic kidney disease-an overview. IJCMR. 2016; 3(4): 1149-1152.

[20] Rebolledo Cobos M, Carmona Lorduy M, Carbonell Muñoz Z, Díaz Caballero A. Salud oral en pacientes con insuficiencia renal crónica hemodializados después de la aplicación de un protocolo estomatológico. Av Odontoestomatol. 2012; 28(2): 77-87.

[21] DeLong L, Burkhart NW. General and oral pathology for the dental hygienist. 3rd ed. Massachusetts: Jones \& Bartlett Learning. 2020.

[22] Lecca Rojas MP, Meza Mauricio J, Ríos Villasis K. Manifestaciones bucales en pacientes con insuficiencia renal crónica en hemodiálisis. Rev estomatol Hered. 2014; 147-54.

[23] Belazelkovska A, Popovska M, Spasovski G, Belazelkovska Z, Minovska A, Mitic K. Oral changes in patients with chronic renal failure. RJOR. 2013; 5(2): 104-12.

[24] GV JAZ, Sautto M. Agrandamientos gingivales inducidos por medicamentos. Una visión genómica y genética. Revisión de la literatura. Rev Mex Periodontol. 2016; 7(1): 25-35.

[25] Montero S, Basili A, Castellón L. Manejo odontológico del paciente con insuficiencia renal crónica. Rev Dent Chile. 2002; 93(2): 14-18.

[26] Oyetola EO, Owotade FJ, Agbelusi GA, Fatusi OA, Sanusi AA. Oral findings in chronic kidney disease: implications for management in developing countries. BMC oral health. 2015; 15(1): 1-8. 